\title{
Aprendizagem de Língua Inglesa e o uso de estratégias: investigando a prática dos aprendizes
}

\author{
Sheilla Andrade Souza ${ }^{1}$ \\ Mauro Daniel Pereira Silva²
}

\section{Resumo}

O objetivo deste artigo é apresentar os dados coletados através de uma pesquisa de Iniciação Científica cadastrada no programa BICJR, em uma instituição federal no interior de Minas Gerais. Buscou-se responder a seguinte pergunta: Quais as estratégias de aprendizagem utilizadas pelos aprendizes participantes desta pesquisa? Partiu-se do princípio de que, durante o processo de aquisição de uma Língua Estrangeira, o uso de estratégias de aprendizagem (OXFORD, 2003) pode favorecer a aprendizagem. Oxford (2003) define estratégias como sendo comportamentos específicos, processos mentais utilizados pelos alunos para enriquecer a aprendizagem, tais como procurar falantes de LE ou encorajar-se para superar as dificuldades de comunicação. Nesse sentido, investigou-se as estratégias utilizadas pelos aprendizes com maiores e menores rendimento escolar. A metodologia utilizada foi o estudo de caso (YIN, 2010). Como resultados, detectou-se que os aprendizes com maiores rendimentos fazem uso constante de estratégias de aprendizagem. Dentre elas, destacam-se as estratégias sociais, cognitivas e de memória. Contrariamente, os participantes com menores rendimentos não relataram fazer uso de estratégias de maneira efetiva e pontuaram dificuldades quanto à organização e ao planejamento de estudo, o que indica a necessidade de desenvolver o uso de estratégias metacognitivas.

Palavras-chave: Ensino de língua. Estratégias de aprendizagem. Aprendizes de língua.

\begin{abstract}
The objective of this paper is to present the data collected through a research of Scientific Initiation enrolled in the program BICJR at a federal institution in the countryside of the state of Minas Gerais. It attempts to answer the following question: "What are the learning strategies used by the participants of this research?". It was assumed that, during second language acquisition process, the use of Learning Strategies (OXFORD, 2003) may help learning. Oxford (2003) defines strategies as being specific behaviors, mental processes used by students to enrich learning, such as looking for FL speakers, or encouraging themselves to overcome communication difficulties. In this sense, it investigates the strategies used by apprentices with higher and lower school performance. The methodology used was the case study (YIN, 2010). As results, it was detected that learners with better school performance make constant use of learning strategies. Among these strategies, social, cognitive and memory strategies are the most common ones. Conversely, participants with lower school performance did not report using strategies effectively and presented difficulties in organizing and planning study, which demonstrates the necessity to help them to learn and use metacognitive strategy.
\end{abstract}

Key-words: Language teaching. Learning strategies. Language learners.

\footnotetext{
1 Doutoranda no Programa de Estudos de Linguagens do CEFET-MG. Mestre em Linguística Aplicada pela Universidade de Brasília (2013). Professora do Instituto Federal de Educação, Ciência e Tecnologia de Minas Gerais - Campus Conselheiro Lafaiete. Desenvolve pesquisa na área do ensino de línguas em contexto técnico e tecnológico dentro da perspectiva dos novos e múltiplos letramentos e da multimodalidade.

2 Estudante do ensino médio do curso de Eletrotécnica e bolsista BICJR no programa de bolsas de iniciação científica do IFTM-Patos de Minas.
}

LínguaTec, Instituto Federal de Educação, Ciência e Tecnologia do Rio Grande do Sul, Bento Gonçalves v. 3, n. 1, p. 20-44, jun. 2019. 


\section{Introdução}

A aquisição ${ }^{3}$ de uma Língua Estrangeira (doravante LE) consiste em um sistema complexo, o qual vários pesquisadores tentam explicar. Para Schütz (2006), a aquisição é um processo de assimilação natural, intuitivo, subconsciente e fruto de interação em situações reais de convívio humano, nas quais o aprendiz participa como sujeito ativo. Segundo ele, uma abordagem inspirada na aquisição valoriza o ato comunicativo e desenvolve a autoconfiança do aprendiz.

Ellis (1985) define aquisição de segunda língua como sendo as formas pelas quais as pessoas aprendem outra língua, além da Língua Materna, dentro ou fora da sala de aula, e que a Second Language Aquisition (doravante SLA), traduzindo, aquisição de Segunda Língua (ASL), é responsável por esse estudo. No que se refere à ASL, Ortega (2009) também a entende como sendo o estudo da capacidade humana de aprender línguas além da primeira, durante a infância, adolescência ou idade adulta, desde que a Primeira Língua (ou Línguas) tenha sido adquirida/aprendida.

Os estudos na área da ASL iniciaram na segunda metade da década de 1960, como sendo interdisciplinar e estabelecendo ligações com outras áreas tais como: ensino de línguas, linguística, aquisição de primeira língua e psicologia. Durante os anos 1980 e 1990, alcançou um crescimento significativo que, ao final do Século XX, se tornou uma disciplina independente. Sendo assim, a ASL utiliza variados termos técnicos que necessitam de uma explicação mais clara, que será apresentada a seguir. Segundo Ortega (2009), pesquisadores utilizam os temos Mother Tongue (Língua Materna) e First Language (Primeira Língua doravante L1), genericamente, para se referirem à/às língua(s) aprendidas pelas crianças por meio dos pais, irmãos, babás, durante a idade crítica - compreendida desde o ventre até os quatro anos de idade. Período que, segunda a autora, com base em pesquisas empíricas, é o que representa a maior parte da linguagem aprendida. Por outro lado, os termos Additional Language (Língua Adicional) e Second Language (Segunda Língua - doravante L2) são

\footnotetext{
${ }^{3}$ Neste trabalho, não faremos distinção entre os termos aquisição/aprendizagem, nem entre Língua Estrangeira/Segunda Língua. Os pares serão tratados como sinônimos.
} 
utilizados para qualquer língua aprendida além da(s) Língua(s) Materna(s).

É importante salientar que a ASL procura entender a aquisição/aprendizagem de LE/L2 tanto em contextos informais quanto formais. Sendo que se entende como contexto informal a aprendizagem de maneira natural por meio de vizinhos, amigos, colegas de trabalho, redes sociais, ferramentas digitais, dentre outros, sem recebimento de instrução formal e sistematizada, e, como contexto formal, a aprendizagem advindas de escolas e universidades: conhecimento organizado e sistematizado, por meio de regras pedagógicas, que incluem o ensino estrutural e comunicativo de uso da língua. Todavia, muitas pessoas aprendem línguas de uma maneira mesclada entre os contextos formal e informal.

Ainda nesse sentido, a ASL tem como objetivo descrever e explicar o processo de aquisição de LE/L2, identificando os fatores internos e externos que influenciam esse processo. Ellis (1997) apresenta, como fatores externos, a situação social na qual a aprendizagem acontece, a qual permite ao aluno ouvir e falar na LE/L2, e as atitudes que os aprendizes desenvolvem, relacionadas à aprendizagem. Conforme o autor, quando existe uma empatia entre aprendizes e nativos, o ambiente será melhor para aprendizagem, diferentemente de quando há relação de hostilidade.

No que se refere aos fatores externos, Ellis (1997) faz referência ao input - insumo, que os aprendizes recebem, aos modelos de linguagem aos quais os aprendizes são submetidos. Para Ellis (1997), não há aprendizagem sem insumo, havendo, assim, uma necessidade de considerar se a qualidade do insumo fornecida aos aprendizes é suficiente para a aprendizagem.

Diante do discutido, sabemos que a aprendizagem de uma LE não é tarefa fácil, exige esforço e dedicação por parte dos aprendizes e dos professores. Nesse sentido, Oxford (1990, 2003) apresenta algumas estratégias que podem auxiliar o processo de ensino e de aprendizagem, a fim de facilitá-lo. Acredita-se que alguns aprendizes já fazem uso inconsciente dessas estratégias, todavia, pontua-se a necessidade de ensiná-las de maneira formal e sistematizada.

Sendo assim, propõe-se, com este trabalho, investigar as estratégias utilizadas pelos aprendizes matriculados no curso de inglês básico do primeiro período de 2017, em um centro de idiomas (doravante CENID), ofertado por uma instituição federal localizada no 
interior de Minas Gerais. A pergunta que norteou a pesquisa foi a seguinte: Quais as estratégias de aprendizagem utilizadas pelos aprendizes participantes desta pesquisa?

Este artigo está organizado da seguinte maneira: em um primeiro momento, apresentará uma revisão bibliográfica referente às discussões acerca das estratégias de aprendizagem; em seguida, exporá a metodologia utilizada e o perfil dos participantes, seguida pela análise e discussão dos dados; por fim, são apresentadas as considerações finais e as referências.

\section{Revisão de Literatura: Estratégias de Aprendizagem}

Aprender uma língua estrangeira é uma tarefa que requer esforço e dedicação por parte do aprendiz. Durante o processo de aprendizagem, cada indivíduo desenvolve estratégias diferentes e possui estilo próprio. Saber combinar as estratégias com os estilos individuais é um grande passo para o sucesso na aprendizagem de um LE.

Os estudos relacionados às estratégias de aprendizagem apareceram na metade da década de 1970, conforme afirmam Brown (2000, p. 123) e Ortega (2009, p. 208). Pesquisas desenvolvidas nessa área foram motivadas pelo desejo de investigar o porquê de alguns aprendizes serem mais bem-sucedidos na aprendizagem de Segunda Língua que outros, e quais fatores determinam essa diferença. Esses estudos mostraram que, além da capacidade natural para aprender línguas e comprometimento com a aprendizagem, os alunos considerados "bons" aprendizes mostravam-se ativamente envolvidos no próprio processo de aprendizagem.

Para melhor entender o uso de estratégias e o processo de aprendizagem de uma Língua Estrangeira, é importante familiarizar-se com termos relacionados ao assunto e que ainda se encontram obscuros ou tidos como sinônimos por alguns pesquisadores. Brown (2000, p. 112) apresenta definições significativas para os seguintes termos: processo, estilo e estratégias.

De acordo com o autor, o conceito de processo é o mais geral dos três. Brown (2000) compara o processo de aquisição de LE com a realização de atividades básicas, tais como respirar ou alimentar-se, afirmando que todo ser humano dotado de inteligência está 
inserido em um processo de aprendizagem. O autor concorda que todos nós estabelecemos relações entre o estímulo e a resposta por meio de um reforço, o que remete à Teoria Behaviorista, também conhecida por Behaviorista-Estruturalista. Essa teoria foi fortemente influenciada por Watson (1924) e Skinner (1957), desempenhando um importante papel no que se refere à aquisição de Primeira e Segunda Língua.

A base de sustentação da Teoria Behaviorista consiste na existência de estímulos resposta, considerando a aprendizagem de qualquer língua conduzida pela formação de hábitos. Watson (1930) define estímulo como sendo qualquer objeto no ambiente geral ou qualquer mudança no organismo devido às condições fisiológicas e resposta como qualquer coisa que o indivíduo faz.

Todavia, quando se refere à Teoria Behaviorista um nome que merece destaque é o de Skinner. O autor laçou em 1957 o livro Verbal Behavior e desde então se consagrou dentro do movimento. Para ele todo comportamento é formado por três eventos importantes: um estímulo - uma resposta - um reforço. Dentro dessa proposta, o indivíduo está exposto a numerosos estímulos do ambiente, a cada estímulo uma resposta é emitida, sendo esta resposta reforçada positiva ou negativamente, gerando, assim, a formação de hábitos.

Ainda para os Behavioristas "a prática gera a perfeição", sendo que a aprendizagem acontece por meio da imitação e repetição de uma mesma estrutura linguística. Acreditam também que o ensino deve ser focado nas estruturas consideras difíceis, nas estruturas que se diferenciam da língua materna.

Na sequência, no que tange ao estilo, por sua vez, na visão de Brown (2000), relaciona-se às diferenças e/ou preferências individuais, referentes às características gerais e intelectuais do aprendiz, tais como idade, atitude, motivação, personalidade, entre outras. Nesse sentido, Willing (1994) citado por Wong e Nunan (2011) apresenta quatro estilos principais derivados a partir das preferências de uso de estratégias dos aprendizes, sendo eles: (1) estilo comunicativo: esses aprendizes foram definidos por seguirem estratégias de aprendizagem, por exemplo: eles gostam de aprender assistindo TV, ouvindo falantes nativos, conversando em L2, usando $L 2$ fora da sala de aula, aprendendo por meio de conversação; (2) estilo analítico: esses aprendizes gostam de estudar gramática, estudar por meio de livros e jornais, geralmente estudam sozinhos, descobrem seus próprios erros, 
resolvem atividades propostas pelos professores; (3) estilo orientado: esses aprendizes preferem que o professor explique todo o conteúdo, preferem ter o próprio livro didático, escrevem/tomam nota, estudam gramática, aprendem por meio de leituras; (4) estilo concreto: esses aprendizes tendem a gostar de jogos, imagens, filmes, vídeo games, interagir com outros interlocutores, praticar a L2 fora da sala de aula.

Quanto às estratégias, conforme Brown (2000), são métodos específicos utilizados pelo aprendiz, a fim de atingir um objetivo, isto é, a produção da língua na modalidade oral e/ou escrita. Elas são planejadas e variam de acordo com o momento e com o objetivo final, podendo ser entendidas como técnicas que o aprendiz desenvolve para resolver um problema em aquisição de LE. Nesse sentido, a ASL vê as estratégias como sendo dividida em dois campos: estratégias de aprendizagem e estratégias de comunicação.

Para reforçar, Ortega (2009) apresenta uma reflexão sobre estilos e estratégias. Estilos são caminhos escolhidos pelo aprendiz para processar informação, e estratégias são procedimentos mentais e comportamentais nos quais os aprendizes se engajam, a fim de obter controle do próprio processo de aprendizagem.

Nesse sentido, pesquisadores como Rubin (1975) e Stern (1975) perceberam a presença de variáveis individuais e descreveram os "bons" aprendizes, pontuando as características pessoais, bem como os estilos e as estratégias utilizadas por eles.

Inicialmente, foram observadas seis características presentes nos considerados como "bons" aprendizes e, posteriormente, Rubin e Thompson (1982) apresentaram quatorze características, sendo elas: (1) encontram caminhos próprios; (2) organizam informação sobre a língua; (3) são criativos; (4) buscam oportunidades para praticar o uso da língua dentro e fora da sala de sala; (5) não se sentem frustrados diante de situações difíceis de uso da língua; (6) usam mnemônica e outras estratégias de memória para recordar o que aprenderam; (7) utilizam os erros a favor da aprendizagem; (8) utilizam conhecimentos linguísticos já possuídos na aprendizagem da Segunda Língua; (9) utilizam o contexto para atribuir significados; (10) precisam aprender como fazer adivinhações inteligentes; utilizam estruturas prontas da língua; (12) aprendem caminhos para manter a conversa; (13) usam técnicas de produção como por exemplo, paráfrase, uso de sinônimos, e pedido de ajuda; (14) aprendem diferentes estilos de discurso e escrita e aprendem como utilizá-los em 
diferentes contextos.

Retomando a aprendizagem de LE, Ellis (1985) cita Faerch e Kasper (1983) que dizem: o aprendiz possui dois tipos de conhecimento - o declarativo (sobre a língua/estrutura) e o procedural (como aprender/uso de estratégias). O conhecimento declarativo consiste em internalizar as regras/estruturas da L2, como, por exemplo: aprender as regras de uso do presente simples (-s de terceira pessoa); e chunks of language - partes da língua/estruturas prontas, a exemplo de: take a chance/ do your homework/ have a nice day/ do you know what I mean?

Já o conhecimento procedural consiste em procedimentos e estratégias empregados pelos aprendizes de LE no processo de aquisição e uso da L2. É dividido em (1) social: compõem estratégias comportamentais usadas pelo aprendiz para administrar oportunidades de interação, por exemplo: contato face-a-face com outros falantes, e com textos em L2; e (2) cognitivo: compõem vários processos mentais envolvidos na internalização e automatização de novos conhecimentos de $L 2$, bem como no uso. Na visão de Ellis (1985), o processo social e cognitivo envolve a aprendizagem e uso da língua. 0 processo de aprendizagem responsável pela forma como o aprendiz acumula os novos conhecimentos de L2 a partir dos insumos. E o processo de uso consiste em estratégias de produção, recepção e comunicação.

Com base nisso, Ellis cita Tarone (1981) que define: (1) estratégias de produção como sendo as tentativas de uso dos conhecimentos existentes em LE de forma eficiente e clara com pouco esforço; (2) estratégias de recepção acontecem quando indivíduo não é capaz de comunicar da forma que gostaria e que planejou, sendo forçado a reduzir ou mudar os planos a fim de se expressar, tanto na forma oral como escrita; (3) estratégias de comunicação, por sua vez, são o resultado de um fracasso inicial na implementação do plano de produção. O uso da língua, portanto, é caracterizado por estratégias de produção e recepção, que operam quando os aprendizes utilizam fontes disponíveis facilmente e subconscientemente. É também caracterizado pelas estratégias de comunicação que operam quando o aprendiz precisa compensar o uso de um significado inadequado, envolvendo esforço e consciência.

Diante do apresentado, vale ressaltar que as estratégias de aprendizagem são 
classificadas e estudadas por vários pesquisadores, dentre eles: Wenden; Rubin (1987); O'Malley; Chamont (1990); Oxford(1990); Ellis, (1994). Embora muitas sejam as tentativas de classificá-las e estudá-las, os resultados não se diferem de forma significativa, apresentando, assim, semelhanças entre as propostas oferecidas pelos teóricos.

Rubin (1987), considerada pioneira no estudo das estratégias, apresenta uma diferença entre as estratégias que contribuem diretamente e outras que contribuem indiretamente para a aprendizagem. A autora disponibiliza três tipos de estratégias apresentadas no quadro a seguir:

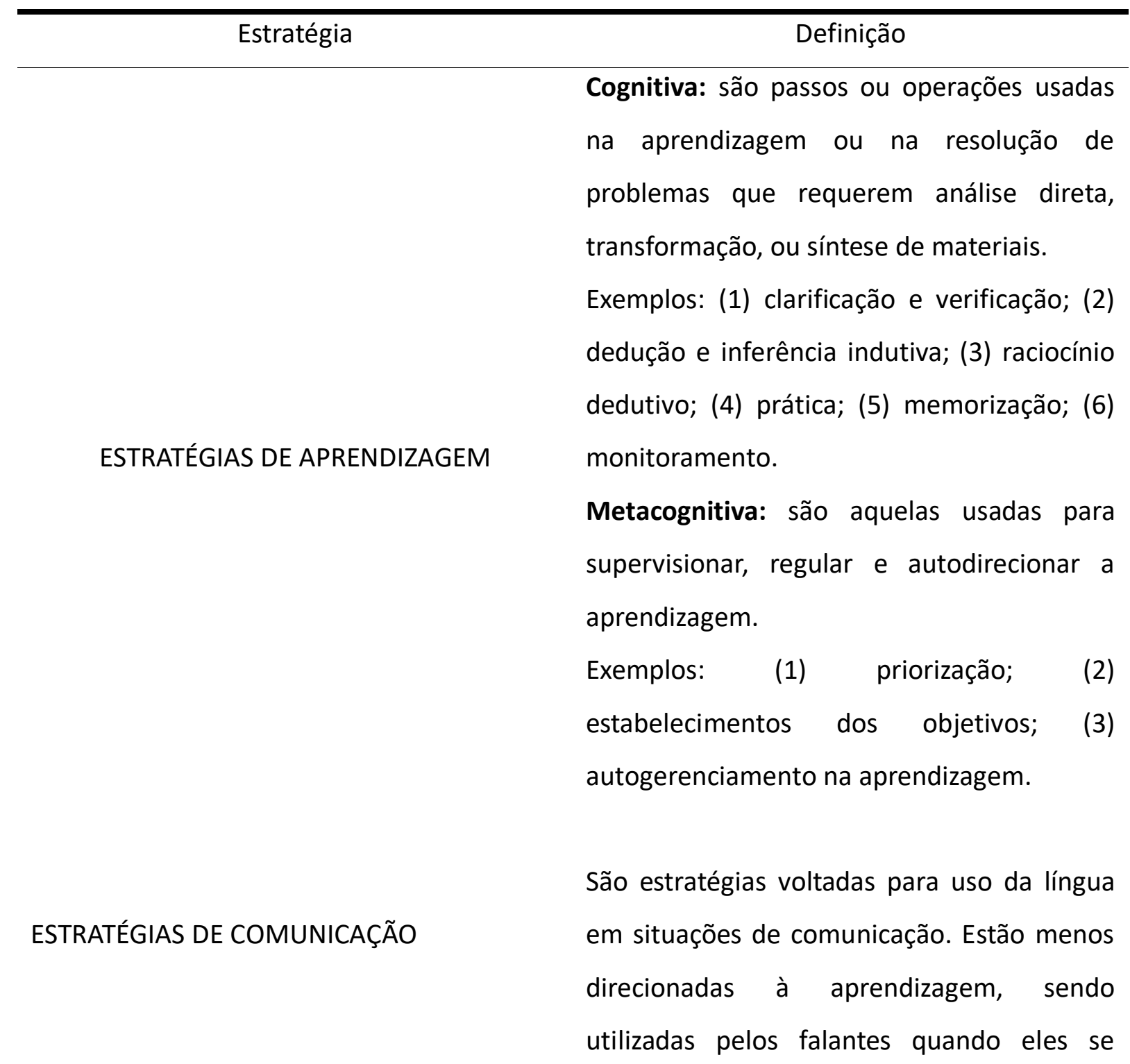


ESTRATÉGIAS SOCIAIS

deparam com dificuldades para expressar suas intenções ou não são compreendidos pelos ouvintes.

Exemplo: uso de conhecimento linguístico ou comunicativos para manter um diálogo, pode ser por meio de gestos, mímicas e uso de sinônimos.

São as atividades que oportunizam aos aprendizes interagirem em contextos de uso de $L E$, permitindo-os praticarem os conhecimentos adquiridos em situações autênticas de uso da língua. Embora essas estratégias forneçam exposição à $L E$, elas contribuem indiretamente para a aprendizagem, uma vez que não conduzem diretamente à obtenção, ao armazenamento e ao uso da língua.

Exemplo: uso da L2 em redes sociais.

Quadro 1: Classificação de estratégias de aprendizagem conforme Rubin (1987)

Fonte: Rubin (1987)

Oxford (1990, 2003), por sua vez, define estratégias como sendo comportamentos específicos, processos mentais utilizados pelos alunos para enriquecer a aprendizagem, tais como procurar falantes de LE ou se encorajar para superar as dificuldades de comunicação. Para Oxford (1990, p. 8), “o uso de estratégias torna a aprendizagem mais fácil, rápida, divertida, autodirecionada, eficaz e mais aplicável e transferível para novas situações".

Assim sendo, a autora elaborou um questionário denominado Strategy Inventory for Language Learning (SILL), com o objetivo de coletar dados esclarecedores sobre como um indivíduo aprende uma LE, o qual foi traduzido pela Professora Doutora Vera Menezes de 
Oliveira e Paiva ${ }^{4}$, da Universidade Federal de Minas Gerais. Para complementar, Oxford (2003) classifica estratégias em seis grandes grupos, a saber:

Estratégias mentais utilizadas pelo aprendiz

Estratégias Cognitivas

Estratégias Metacognitivas

Estratégias de Memória

\section{Estratégias Compensatórias}

Estratégias Afetivas para dar sentido à aprendizagem.

Exemplo: tomar notas, resumir, esquematizar.

Permite ao aprendiz organizar a própria aprendizagem, identificar o estilo e as necessidades de aprendizagem.

Exemplo: monitorar os erros, planejar o local e horário para estudo.

Ajuda o aprendiz a estabelecer ligação com a L2, utilizada para armazenar informações.

Exemplo: conectar uma palavra com uma imagem ou som, movimento corporal.

Permite ao aprendiz superar as dificuldades e continuar a comunicação (por exemplo: uso de sinônimos, gestos...);

Relacionadas ao emocional do aprendiz, tais como: ansiedade, confiança.

\footnotetext{
${ }^{4}$ Disponível em < http://www.veramenezes.com/sill.htm>.
} 
Exemplo: encorajar-se diante de situações de uso da língua.

Estratégias Sociais

Ajuda o aprendiz a interagir com os outros falantes e entender a cultura-alvo e o funcionamento da L2.

Exemplo: pedir ajuda ao desenvolver uma tarefa, fazer perguntas para ajudar na compreensão.

Quadro 2: Classificação de estratégias de aprendizagem conforme Oxford (2003)

Fonte: Oxford (2003)

Ainda relacionado ao assunto, O'Malley e Chamont (1990) definem estratégias como sendo pensamentos e comportamentos especiais utilizados pelos aprendizes para compreender e reter informações novas. Os autores apresentam outro modelo de classificação semelhante ao de Oxford (1990), no qual eles dividem as estratégias em três grupos, conforme visto a seguir:

\begin{tabular}{ll}
\hline Estratégia & \multicolumn{3}{c}{ Exemplos } \\
\hline Estão relacionadas ao conhecimento, \\
controle $\quad$ e regulamentação da \\
aprendizagem. Requer planejamento, e \\
consciência sobre $\quad$ processo de \\
aprendizagem. \\
Exemplos: \\
Planejamento: Previsão das ideias principais \\
e conceitos de materiais a serem \\
aprendidos, pelo uso de estratégias de \\
leitura. \\
Atenção Direcionada: Decidir previamente
\end{tabular}


assistir determinadas atividades de aprendizagem ignorando os elementos de distração.

Planejamento Funcional: Planejamento e ensaio dos componentes linguísticos necessários para desempenhar uma tarefa. Atenção Seletiva: Decidir previamente participar de inputs específicos, frequentemente buscando palavras-chaves, conceitos, e marcadores linguísticos.

Autogerenciamento na aprendizagem: entender as condições que conduzem a aprendizagem e buscar essas condições.

Monitoramento: Verificar a compreensão durante atividades orais e escritas, e a precisão e apropriação do output oral e escrito.

Avaliação: checar os resultados comparando com os padrões.

São mais restritas a tarefas específicas e envolvem manipulação direta de materiais.

Exemplos:

ESTRATÉGIAS COGNITIVAS

Recurso: uso de materiais na Língua Alvo como dicionários, enciclopédias, ou livro texto.

Repetição: inclusão de imitação de modelos da Língua Alvo, incluindo práticas em voz alta ou silenciosa; 
Agrupamento: classificar palavras, terminologias, ou conceitos, de acordo com seus atributos e significados.

Dedução: aplicar regras para compreensão ou produção de Segundo Língua ou elaborar regras baseadas em observações.

Imagens: uso de imagens mentais, ou reais, para entender ou lembrar de informações novas.

Representação Auditiva: planejar na mente o som de uma palavra, frase, ou uma sequência de frases.

Uso de Palavra-Chave: relembrar uma palavra nova em Segunda Língua por: (1) identificar uma palavra parecida em Primeira Língua que soa parecida com a nova; (2) recordar facilmente a relação entre homônimos em Primeira Língua com palavras novas em Segunda Língua.

Elaboração: relacionar informações novas com conhecimento prévio, relacionar diferentes partes de novas informações com outras, ou fazer associações pessoais significativas com as novas informações.

Transferência: usar conhecimento linguístico ou habilidades prévias para ajudar na compreensão ou produção.

Inferência: usar informações disponíveis para adivinhar significados, prever 
resultados, ou completar informações perdidas.

Anotação: escrever palavras-chave ou conceitos de forma gráfica, verbal ou numérica enquanto lê ou ouve em L2.

Resumir: fazer um resumo mental, oral ou escrito das novas informações obtidas através de atividades orais ou escritas.

Recombinar: construir sentenças significativas e/ou sequenciais de frases combinando elementos já conhecidos Tradução: usar a Primeira Língua como base para compreensão e/ou produção de L2.

São relacionadas à interação e à cooperação. Exemplos:

Fazer Perguntas: extrair dos professores, colegas, informações adicionais, reformulação de frases, exemplos, ou ESTRATÉGIAS SOCIAIS confirmação.

Cooperação: trabalhar em grupo com pessoas ou mais colegas a fim de resolver problemas, checar as tarefas de aprendizagem, ou obter feedback sobre o desempenho oral ou escrito.

Quadro 3: Classificação de estratégias de aprendizagem conforme O’Malley e Chamont (1990) Fonte: O'Malley e Chamont (1990)

Como dito e apresentado acima, vários estudiosos definem e classificam as estratégias de aprendizagem de línguas. Neste trabalho, adota-se a definição apresentada por Oxford (1990, 2003), bem como a classificação das estratégias expostas pela autora. 
Entende-se que o uso de estratégias desempenha um papel fundamental no processo de aquisição/aprendizagem de LE podendo levar ao sucesso da aprendizagem e conduzir os aprendizes na direção do que Rubin e Thompson (1982) denominam bons aprendizes de línguas. Na sequência, apresenta-se a metodologia utilizada para condução da pesquisa.

\section{Metodologia}

A metodologia utilizada consiste em um estudo de caso. Sendo assim, de acordo com Yin (2010, p. 39), o estudo de caso "é uma investigação empírica que investiga um fenômeno contemporâneo em profundidade e em seu contexto de vida real, especialmente quando os limites entre o fenômeno e o contexto não são claramente evidentes".

Os participantes foram 4 (quatro) alunas do curso Basic I, matriculadas no Centro de Idiomas (CENID), em uma escola pública no interior de Minas Gerais. O critério de seleção dos participantes se deu com base nas observações realizadas, pela professora-pesquisadora, durante as aulas, relacionadas à participação e desempenho, das alunas. Assim como, devido à análise das notas obtidas durante o primeiro semestre de 2017 . Foram distribuídos 100,0 (cem) pontos, sendo 39,0 (trinta e nove) pontos referentes às atividades orais e 61,0 (sessenta e um) pontos relacionados às atividades escritas.

Vale pontuar que, em termos quantitativos, o rendimento das participantes selecionadas reforçaram as observações da professora-pesquisadora. Em outras palavras, as alunas que apresentavam maiores dificuldades quanto ao uso da $\mathrm{LI}$ no que se refere às habilidades orais e escritas, apresentaram notas mais baixas. Ao contrário, as duas alunas mais participativas, que realizavam as atividades e demonstravam interesse durante as aulas, por meio de questionamentos e iniciativa de uso da LI, obtiveram as notas maiores. Dessa forma, selecionou-se as duas alunas com maiores notas e outras duas com as menores notas, e realizou-se um estudo comparativo.

Reconhece-se que vários são os fatores que interferem na aquisição/aprendizagem de uma LE, assim sendo, Ellis (1985) aponta fatores de ordem pessoal e geral. Para o autor, esses fatores apresentam aspectos sociais, cognitivos e afetivos. Os aspectos sociais são externos ao aprendiz e referem-se ao uso da língua a partir da interação com nativos e não nativos da 
LE. Os fatores cognitivos e afetivos são internos. Sendo os cognitivos referentes ao uso de estratégias para a solução de problemas de comunicação, enquanto, os fatores afetivos estão relacionados aos aspectos emocionais envolvidos na tentativa de aprender LE.

Para o autor, os fatores pessoais são difíceis de serem identificados por uma terceira pessoa, sugere-se então, que o aprendiz registre suas experiências de aprendizagem de LE em diários. Para exemplificar os fatores pessoais, Ellis (1985) cita: dinâmica de grupo, atitude do professor, material didático, técnicas individuais de aprendizagem. Quanto aos fatores gerais, Ellis (1985) apresenta: idade, atitude, estilo cognitivo, motivação e personalidade.

Salienta-se que não é objetivo neste artigo discutir detalhadamente esses fatores, pretende-se apenas detectar quais as estratégias de aprendizagem utilizadas pelos aprendizes com maiores e menores notas. Para delimitação desse critério, levou-se em consideração que trata-se de uma pesquisa de Iniciação Científica, dessa forma, não configura-se interesse esgotar o tema.

\begin{tabular}{|c|c|c|c|}
\hline \multicolumn{4}{|c|}{$\begin{array}{c}\text { PARTICIPANTES COM MENOR RENDIMENTO - } 100 \text { PONTOS DISTRIBUÍDOS } \\
\text { Atividades orais e escritas }\end{array}$} \\
\hline Participantes & Idade & Sexo & Notas \\
\hline P1 & 47 & Feminino & 65,20 \\
\hline P2 & 33 & Feminino & 69,60 \\
\hline \multicolumn{4}{|c|}{$\begin{array}{c}\text { PARTICIPANTES COM MAIOR RENDIMENTO - } 100 \text { PONTOS DISTRIBUÍDOS } \\
\text { Atividades orais e escritas }\end{array}$} \\
\hline P3 & 14 & Feminino & 98,60 \\
\hline P4 & 27 & Feminino & 94,60 \\
\hline
\end{tabular}

Quadro 4: Perfil dos participantes

Fonte: Dados da pesquisa

Para a coleta de dados, utilizou-se a planilha final de notas e frequências fornecidas pelo sistema acadêmico, e foi aplicado um questionário contendo 3 (três) perguntas relacionadas ao perfil dos participantes e 9 (nove) referentes ao uso de estratégias de aprendizagem de LE, as quais serão apresentadas e analisadas a seguir.

\section{Análise e discussão dos dados}


O processo de aquisição de LE exige dos aprendizes um papel agentivo, o desenvolvimento de estratégias que podem auxiliar o processo. Como visto acima, além da capacidade natural de aprender línguas e do compromisso com a aprendizagem, os alunos considerados "bons" aprendizes mostravam-se ativamente envolvidos no próprio processo de aprendizagem. Dito isso, nesta seção, serão apresentadas estratégias utilizadas pelos considerados "bons aprendizes" e pelos "aprendizes com dificuldades". Salienta-se que essas classificações foram estabelecidas com base em observações realizadas pela professorapesquisadora, e a partir dos resultados quantitativos apresentados pelos aprendizes. Em um primeiro questionamento, perguntou-se aos participantes:

\section{Conte como você aprendeu ou tem aprendido língua inglesa.}

\section{Participantes com notas menores}

P1: Eu estou tendo muita dificuldade, pois desde 1990 não estudo, não faço nada, então me sinto com a mente e raciocínio acomodado. Mas vou me esforçar, incomodar meus colegas, pois quero aprender.

P2: Tenho aprendido bem pouco, eu tenho muita dificuldade em aprender inglês.

\section{Participantes com notas maiores}

P3: Tenho aprendido língua inglesa por intermédio das aulas do centro de idiomas, bem como pela realização de jogos interativos que permitem exercitar a pronúncia, a leitura, o compreendimento oral, entre outros aspectos.

P4: Participo das aulas semanalmente, desenvolvo as atividades propostas tanto em sala quanto em casa. A prática de atividades escritas e orais ajudam bastante, bem como utilização de redes sociais em inglês, filmes e séries em inglês com legenda em português.

\section{Quadro 5: Primeira pergunta analisada a partir do questionário aplicado}

Fonte: Dados da pesquisa

Ao observar os dados, percebe-se que as participantes com notas inferiores mencionam dificuldade quanto à aprendizagem de inglês. Porém, não citam atitudes concretas que favoreçam a aprendizagem. Percebe-se, portanto, a ausência do 
conhecimento procedural. Nesse sentido, a P1 diz que irá se esforçar e incomodar os colegas, mas usa o verbo no futuro, sugerindo uma ação ainda não concretizada. É interessante pontuar, embora essa questão não seja discutida neste trabalho, que P1 e P2 são as alunas com as maiores idades da turma, tendo 47 anos e 33 anos respectivamente. Quanto a isso, limita-se aqui a dizer que, segundo Oxford (1994), alunos de diferentes idades e níveis de LE utilizam diferentes estratégias.

Já P3 e P4, aprendizes com maiores notas, afirmam participarem das aulas do Cenid e buscarem outras formas de aprendizagem e contato com a $\mathrm{LI}$ fora do contexto escolar, mesclando, assim, a aprendizagem no contexto formal e informal. Os depoimentos de P3 e P4 indicam que, além do insumo recebido em sala de aula, elas buscam outros, fora desse contexto, o que remete a Ellis $(1997$, p. 5), que afirma não haver aprendizagem sem insumo.

Conforme Rubin (1975), tem se observado que os "bons aprendizes" aproveitam e criam oportunidades para praticar o que eles têm aprendido, enquanto os poorer learners (RUBIN, 1975) - aprendizes com menor desempenho -, passivamente, fazem somente o que a eles é solicitado. Para a autora, os "bons aprendizes" de língua usam-na quando não são solicitados e procuram oportunidades para ouvi-la (assistem filmes na língua estrangeira, juntam-se a clubes de falantes estrangeiros, ouvem TV ou rádio, usam a língua estrangeira com alunos fora da sala de aula), atitudes essas percebidas em P3 e P4. Em uma segunda pergunta, tem-se:

Quando você quer dizer uma palavra, mas não sabe ou esqueceu, como você age? 0 que faz para que a comunicação continue?

\section{Participantes com notas menores}

P1: Peço ajuda com quem estou falando.

P2: Gestos.

\section{Participantes com notas maiores}

P3: Quando desejo dizer um termo, mas o esqueço, procuro sinônimos da palavra. No entanto, há momentos em que não consigo identificá-los e, assim, digo que sinto muito e que não consigo dizer o que desejo.

P4: Tento induzir a outra pessoa a entender o contexto que estou explicitando na fala, ou pergunto em português. 
Quadro 6: Segunda pergunta analisada a partir do questionário aplicado Fonte: Dados da pesquisa

Diante das respostas, percebe-se que as quatro participantes fazem uso de estratégias para conduzir a comunicação. P1 e P4 empregam as estratégias sociais, pois ambas interagem com o interlocutor solicitando ajuda. P2 e P3 valem-se das estratégias compensatórias. P2 faz gestos e P3 usa sinônimos. Os depoimentos dos participantes dialogam com Rubin (1975), para quem os bons aprendizes de língua têm uma forte predisposição para comunicar ou aprender através da comunicação. Eles usam gestos ou soletram/escrevem a palavra quando a pronúncia não é clara, usam cognatos, tentam várias formas para expressarem os significados.

Vale destacar que P4, ao deparar-se com uma dificuldade maior, emprega uma estratégia de compensação: uso da Língua Materna. Isso pode ser justificado pelo fato de estar no nível básico, e, possivelmente, há ausência de vocabulário e estruturas linguísticas, o que se pressupõe que será superado, uma vez que a participante é assídua e se mostra interessada em aprender. Na sequência, apresenta-se mais uma pergunta extraída do questionário.

Você costuma deduzir os significados das palavras de acordo com o contexto? 0 fato de você não saber o significado de uma palavra atrapalha a comunicação? Explique.

\section{Participantes com notas menores}

P1: Atrapalha sim. Porque tenho dificuldade de entender o contexto.

P2: Sim. Procuro tentar deduzir, e quando não sei o significado da palavra, me perco por completo na comunicação.

\section{Participantes com notas maiores}

P3: Sim. Comumente, identifico a significação de palavras a partir do contexto no qual elas se encontram inseridas. O fato de não saber o significado de uma palavra não atrapalha a comunicação singularmente em função do supracitado.

P4: Na maioria das vezes, consigo entender, de forma geral, o diálogo, mesmo que haja palavras que eu não saiba o significado, pois, pelo contexto, é possível inferir o significado de algumas (poucas) palavras. 
Quadro 7: Terceira pergunta analisada a partir do questionário aplicado

Fonte: Dados da pesquisa

Nota-se que as participantes com notas menores afirmam terem dificuldades para prosseguirem com a comunicação ao se depararem com palavras desconhecidas. Embora P2 tenha dito que tenta deduzir um significado, ela alega perder-se na comunicação quando isso acontece. Já as participantes com notas maiores asseguram que o contexto permite a identificação de palavras desconhecidas e possibilita a inferência de significados. Segundo P3, "[o] fato de não saber o significado de uma palavra não atrapalha a comunicação". Isso indica que as participantes P3 e P4 são good guessers - boas adivinhadoras, característica essa apontada por Rubin (1975), presente nos “bons aprendizes", que estão dispostos a adivinharem os significados a partir das pistas deixadas pelo contexto. Eles utilizam os conhecimentos gramaticais e lexicais que já possuem, fazem associações entre o verbal e o não verbal, além de fazerem inferências sobre o significado das palavras desconhecidas. Por fim, segue a última pergunta analisada.

Redija um texto contando quais as estratégias você utiliza para ajudar no seu processo de aprendizagem de língua inglesa. $O$ que você faz para melhorar seu aprendizado, se você se considera um bom aprendiz de inglês, se você se dedica dentro e fora da sala de aula, como você estuda para as provas, se/como você associa os significados de palavras novas com imagens, sons etc.

\section{Participantes com notas menores}

P1: Para mim, é tudo muito difícil, pois não me considero um bom aprendiz. Tenho dificuldade, não tenho tempo para me dedicar fora da sala de aula e preciso aprender até como me organizar para estudar. Estou aprendendo aos poucos a usar imagens e sons para compreender o contexto.

P2: Primeiramente, por falta de tempo, não utilizo de outras estratégias para melhorar o processo de língua inglesa, mesmo não me considerando uma boa aprendiz. Pretendo combinar, com uma colega de sala, para estudarmos juntas, em casa. No caso, para estudar para provas, dou uma revisada rápida no conteúdo. No entanto, sei que não é suficiente, pois o conteúdo tem que ser estudado mais profundo.

Participantes com notas maiores

P3: Com o intuito de melhorar o meu aprendizado, busco constantemente realizar exercícios em casa que envolvam o que foi falado em sala, realizando o mesmo a fim de estudar para as provas. Quando aprendo palavras novas, almejo igualmente, associar às imagens, sons, 
dentre outros. Considerando que poderia ser uma aluna melhor de inglês caso estudasse mais.

P4: Participo ativamente das aulas, questiono sobre quaisquer termos/palavras/expressões que sejam novas ou desconhecidas. Procuro repetir a pronúncia de tudo que é aprendido na sala de aula, realizando as tarefas diárias dentro e fora dela.

Ultimamente, estudo somente para as provas relendo o conteúdo aprendido, reescrevendo e pronunciando. Tenho hábito de assistir seriados e filmes em inglês, porém sempre com legenda em português.

Quadro 8: Quarta pergunta analisada a partir do questionário aplicado Fonte: dados da pesquisa

Com base nos dados coletados, observa-se que as participantes com maiores rendimentos relatam fazerem uso de estratégias de aprendizagem, a saber:

$\checkmark$ P3 e P4: realizam atividades fora da sala de aula: estratégias cognitivas.

$\checkmark$ P3: busca fazer associações: estratégias de memória.

$\checkmark$ P3 e P4: participam das aulas, questionam: estratégias sociais.

$\checkmark$ P3 e P4: procuram outras formas para aprender (assistir filmes): estratégias cognitivas e sociais.

Já as participantes com menores rendimentos afirmam:

$\checkmark$ P3: tem dificuldade e diz não saber se organizar para estudar: não aplicação da estratégia metacognitiva.

$\checkmark$ P4: menciona que irá combinar de estudar com uma colega: não aplicação de estratégia social.

$\checkmark$ P3 e P4 mencionam a falta de tempo: não aplicação da estratégia metacognitiva.

Face a esse paralelo, entende-se que os aprendizes com maiores rendimentos escolar afirmam fazerem uso de estratégias de aprendizagem para auxiliarem na aquisição de LI. Detectou-se o uso de estratégias cognitivas, sociais e de memória. Quanto aos participantes com menores rendimentos, estes relataram dificuldades e falta de tempo para se dedicarem, 
além de que, nestes depoimentos, não mencionaram o uso de estratégias. P1 aponta a necessidade de organização do tempo para estudo, revelando, assim, a ausência da estratégia metacognitiva, a qual, segundo Oxford (2003), é a estratégia que permite ao aprendiz organizar sua própria aprendizagem, planejando o horário e o local de estudo.

P4, por sua vez, diz que pretende organizar-se para estudar com uma amiga, isto é, refere-se a uma ação futura, o que indica que, embora a participante tenha consciência de que a utilização de estratégia social poderá contribuir para a aprendizagem de LE, ela ainda não iniciou o processo e não relatou de forma clara os fatores que interferem no processo, podendo ser de ordem geral ou pessoal, como dito por Ellis (1985). Por fim, ambas alegam falta de tempo para se dedicarem, novamente, indicando a não aplicação da estratégia metacognitiva.

Os dados apresentados caminham na direção do dito por Rubin (1975), no sentido de ser possível que os professores ajudem os alunos que apresentam menor rendimento a melhorarem suas performances por meio da conscientização do uso de estratégias. Nesse contexto específico, verificou-se que os alunos com dificuldades deixam de usar ativamente as estratégias no processo de aprendizagem de LI. Segue-se com as considerações finais.

\section{Considerações finais}

A aquisição/aprendizagem LE é um processo complexo, no qual vários elementos estão envolvidos. Dentre esses elementos, destacamos o uso de estratégias que auxiliam no processo. Quanto às estratégias, várias classificações são apresentadas por diferentes pesquisadores. De maneira geral, são parecidas e apresentam poucas diferenças entre os modelos, sendo as estratégias, basicamente, divididas em estratégias cognitivas, metacognitivas e sociais.

No decorrer deste trabalho, almejou-se responder a seguinte pergunta: Quais as estratégias de aprendizagem utilizadas pelos aprendizes participantes desta pesquisa? Para isso, selecionou-se quatro participantes, os dois com maiores rendimentos e os dois com menores rendimentos matriculados no nível básico em um curso de idiomas ofertado por uma instituição federal. Os dados revelaram que os participantes com menores rendimentos 
relatam dificuldades quanto à aprendizagem de LI e não deixam claro quais as estratégias de aprendizagem são utilizadas por eles, efetivamente. De maneira geral, alegam falta de tempo para se dedicarem, o que permite pensar que, possivelmente, a compreensão e o uso de estratégias metacognitivas, poderiam ser úteis para ajudar na aprendizagem. Como, por exemplo: identificar o próprio estilo de aprendizagem e elaborar um plano e horário de estudo. É importante notar que os participantes com menores rendimentos são adultos e desempenham várias funções além de estudar, o que pode ocasionar a ausência de tempo para dedicar à aprendizagem de LI.

Quanto aos participantes com maiores rendimentos, detectou-se o uso das estratégias sociais, cognitivas e de memória. Conforme os dados, eles afirmam buscarem outros insumos além dos recebidos em sala de aula: assistem filmes e séries em LI, procuram escrever, pronunciar e memorizar falas, palavras e frases estudadas em sala, dentre outras estratégias. A respeito disso, sabe-se que, para aprender uma LE, é necessário esforço e dedicação por parte dos aprendizes. Cabe a eles se dedicarem, também fora da sala de aula, e buscarem situações de interação que promovam o uso da LE, como, por exemplo, usar as redes sociais para praticarem LE, criar grupos de estudo e prática tanto presencial quanto online, ouvir música, navegar em sites, dentre outros.

Diante das discussões, é importante ressaltar que os professores de línguas desempenham um importante papel no processo de ensino e de aprendizagem de LE. Eles são responsáveis por prepararem atividades que promovam a motivação e atendam aos interesses dos aprendizes, respeitando os diferentes estilos de aprendizagens. É fato que em uma mesma sala de aula, os aprendizes apresentam diferentes estilos de aprendizagem, motivação variadas para estudar, e objetivos diferentes quanto à aprendizagem de uma LE, portanto, o professor deve fazer uso de uma gama de recursos a fim de suprir as necessidades de cada aprendiz. É interessante que ele trabalhe um mesmo tema a partir de atividades visuais, orais, auditivas e escritas para atender aos diversos estilos.

Isso pode ser feito com vídeos, música, e material impresso e/ou digital. Como atividade prática, pode ser solicitado que o aluno conte sobre sua rotina, uma viagem que realizou, se apresente aos colegas, fale/escreva sobre pontos turísticos da sua cidade, além de outros tópicos. Essas atividades podem ser realizadas de forma oral (em sala de aula e/ou 
por meio de vídeos e áudio) e/ou escrita (por meio da tela) assim, contempla-se os multiletramentos ${ }^{5}$, tema esse que não será discutido neste trabalho.

Sugere-se que os professores ensinem aos aprendizes como fazer uso das estratégias de aprendizagem e forneçam subsídios para que esses se tornem ativos e conscientes no processo de aquisição de LE. Nesse sentido, como continuação desta pesquisa foi desenvolvido um projeto intitulado "Aprender uma língua estrangeira: uma questão de estratégia", com o objetivo de conscientizar e orientar os alunos sobre quais e como as estratégias poderiam ser utilizadas para a melhora da aprendizagem.

Em síntese, o professor de línguas precisa, ainda, ser reflexivo sobre sua prática pedagógica, avaliando o método utilizado, os recursos didáticos e as diferentes formas de avaliação, sendo capaz de promover a autonomia no aprendiz.

\section{Referências}

ALMEIDA FILHO. J.C.P. Dimensões comunicativas no ensino de língua. Campinas: Pontes, 1998.

ALMEIDA FILHO. Lingüística aplicada, ensino de línguas e comunicação. Campinas:Pontes/Artelingua, 2005.

ELLIS, R. Study of second language acquisition. Oxford: Oxford University Press, 1997.

ELLIS, R. Understanding second language acquisition. Oxford: Oxford University Press, 1985.

KRASHEN, S. Second language acquisition and second language learning. Oxford: Pergamon, 1982.

MITCHELL, R.; MYLES, F. Second language learning theories. London: Arnold, 2004.

O'MALLEY, J.M; CHAMOT, A.U. Learning strategies in second language acquisition. Cambridge, U.K.: Cambridge University Press, 1990.

ORTEGA, L. Understanding second language acquisition. London: Hodder Education, 2009.

OXFORD, R L. Language learning strategies: What every teacher should know. New York: Newbury House. 1990.

\footnotetext{
${ }^{5}$ Para sabe mais ver Souza (2013) disponível em

<http://repositorio.unb.br/bitstream/10482/16314/1/2013 SheillaAndradedeSouza.pdf>
}

LínguaTec, Instituto Federal de Educação, Ciência e Tecnologia do Rio Grande do Sul, Bento Gonçalves v. 3, n. 1, p. 20-44, jun. 2019. 
OXFORD, R L. R L. Language learning styles and strategies: an overview. Learning Styles\&Strategies/Oxford, Gala, 2003.

PAIVA, V.L.M.O. A complexidade da aquisição de segunda língua: revisando e conciliando teorias - Modelo da Gramática Universal. 2008b Disponível em: http://www.veramenezes.com/aquisicao.htm. Acesso em: 10 nov. 2011.

PAIVA, V.L.M.O. A complexidade da aquisição de segunda língua: revisando e conciliando teorias - Modelo Monitor, Hipótese do input ou da compreensão. 2008c. Disponível em: http://www.veramenezes.com/aquisicao.htm. Acesso em: 10 nov. 2011.

PAIVA, V.L.M.O. A complexidade da aquisição de segunda língua: revisando e conciliando teorias - Teoria Behaviorista-estrutural. 2008d. Disponível em: http://www.veramenezes.com/aquisicao.htm. Acesso em: 10 nov. 2011.

RUBIN, J., Thompson, I. How to become a more successful language learner. Boston, MA: Heinle \& Heinle, (1982).

SCHÜTZ, R. Assimilação natural x ensino formal. Disponível em: https://www.sk.com.br/sklaxll.html. Acesso em: 22 maio 2019.

SKINNER, B. F. Verbal behavior. New York: Applenton-Century-Crofts. 1957.

STERN, H H. What can we learn from the good language learner? The Canadian Modern Language Review, Toronto, v. 31, n.4, p. 304-318, 1975. Disponível em: https://doi.org/10.3138/cmlr.31.4.304. Acesso em: 22 maio 2019.

WATSON, J. B. Behaviorism. New York: Norton, 1930.

WONG, L. L.C., NUNAN, D. The learning styles and strategies of effective language learners. System 39. p. 144-163. 2011.

WENDEN, A. RUBIN, J. Learner strategies in language learning. Englewood Cliffs, NJ: Prentice Hall International. 1987.

YIN, R. Estudo de caso: planejamento e métodos. Porto Alegre: Bookmann. 2010.

Data de submissão: 03/04/2019. Data de aprovação: 14/05/2019. 